\title{
Wait times increasing for hip and knee replacement
}

$\mathrm{C}$ anadians are waiting longer for hip- and knee-replacement surgery despite an increase in priority procedures performed in hospitals, says a new report by the Canadian Institute for Health Information (CIHI).

Wait Times for Priority Procedures in Canada, 2013 found that between 2010 and 2012, the number of Canadians receiving knee- or hip-replacement surgery within the targeted wait period of 182 days dropped by $4 \%$. The benchmark wait periods were set by the Canadian Institutes of Health Research (CIHR) in 2004 at the request of federal and provincial governments for the First Ministers' initiative, A 10-Year Plan to Strengthen Health Care.

The 10-year plan's stated goal was to reduce wait times in five priority areas, with $90 \%$ of Canadians receiving treatment within the benchmarks by 2014. The provinces did not reach that goal, the report states. CIHI reports annually on the plan's progress, and this year collected data for five of eight priority procedures, including cataract surgery, radiation therapy and hip fracture repair.

It's a complicated problem," says Kathleen Morris, director of health system analysis and emerging issues at $\mathrm{CIHI}$.

There were more procedures performed in 2012 than in any previous year, Morris says, but the provinces aren't keeping up with rising demand. "They're chasing a moving target because there's an increasing number of people queuing up [for treatment]."

The report acknowledges that each province came from a different starting point regarding health care. Morris says that the provinces have done a lot of work recently to improve access.

"The feeling that most of us have is that we're getting close to the maximum efficiency we can have while still being safe," says Dr. James Waddell, an orthopedic surgeon at St. Michael's Hospital in Toronto, Ontario. "We don't want to cut corners."
Waddell says that in Ontario the number of patients on the wait list has gone up. "We have to be sensitive to the fact that we're dealing with [health] care here," he says, adding that health providers shouldn't make assumptions about the abilities or resources of patients. "Each case has to be individualized."

Yet wait times are not always involuntary, and current data collection methods aren't perfect, says Dr. Cy Frank, executive director of the Alberta Bone and Joint Health Institute.

"A lot of people are choosing to wait for particular surgeons, rather than being forced to wait," Frank says.

This could possibly skew results in the report. "That turns out to be 20 to $30 \%$ of people on the waiting list," he says, speaking from anecdotal evidence. "If a lot of patients are waiting for one person who has a great reputation, that's just not a system failure." Cullen Bird, CMAJ

CMAJ 2013. DOI:10.1503/cmaj.109-4445

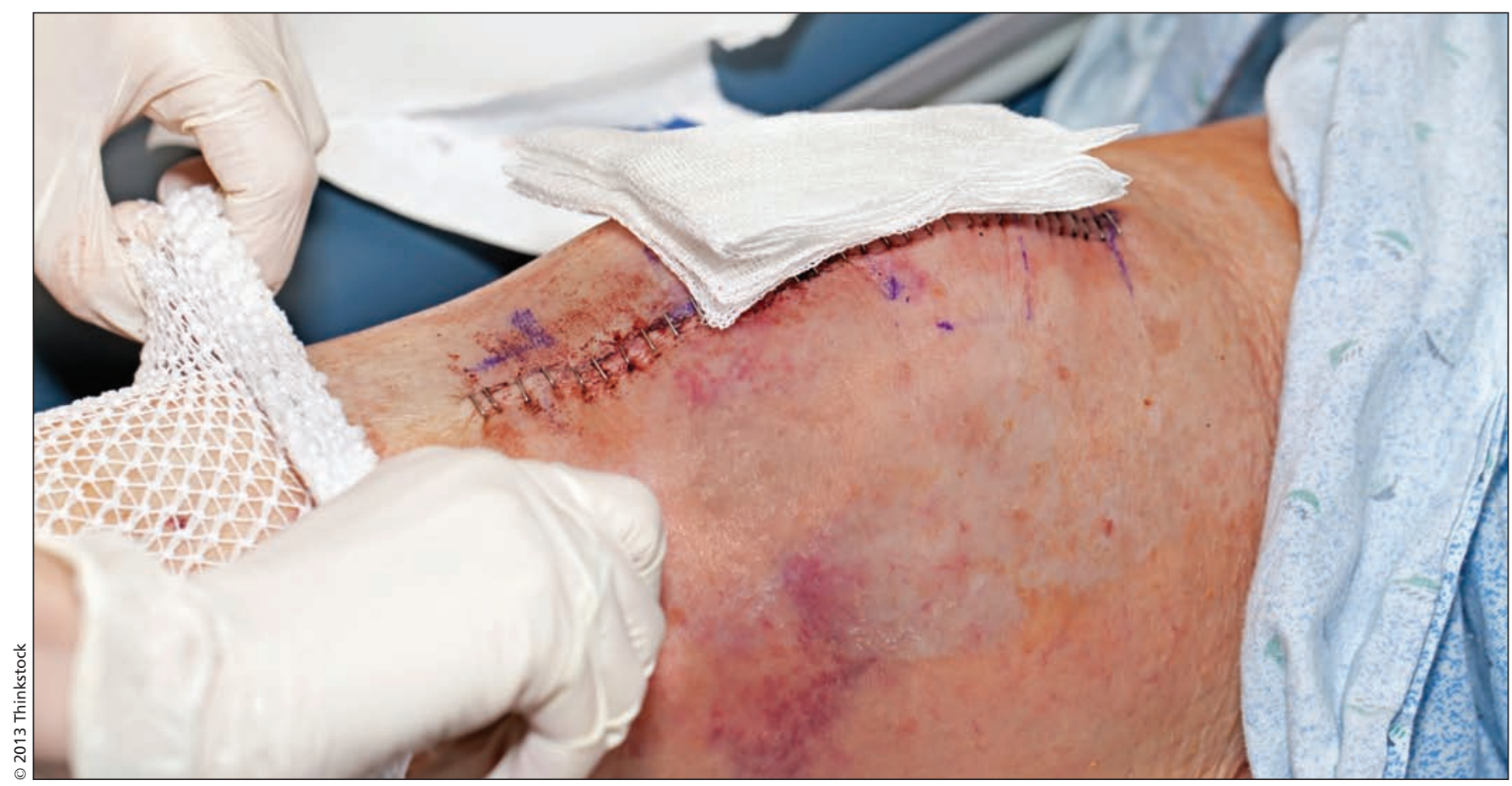

Between 2010 and 2012, the number of Canadians receiving knee- or hip-replacement surgery within the targeted wait period of 182 days dropped by $4 \%$, according to the Canadian Institute for Health Information. 